Dokuz Eylül Üniversitesi-Mühendislik Fakültesi

Fen ve Mühendislik Dergisi

Cilt 19 Sayı 55.1(Özel Sayı) Ocak 2017
Dokuz Eylul University-Faculty of Engineering Journal of Science and Engineering Volume 19 Issue 55.1. (Special Issue) January 2017

DOI: $10.21205 /$ deufmd.2017195529

\title{
GPS Mesajlarının Nesneye Yönelik Yazılım Tasarım Prensiplerinden Genişlemeye Açık, Değişikliğe Kapalı Prensibine Göre Ele Alınması
}

\section{Mehmet Mustafa GÜRSUL ${ }^{* 1}$, Muhammed Ali ASAN ${ }^{2}$, Tahsin Alp YANAR ${ }^{3}$}

${ }^{1}$ Savunma Teknolojileri Mühendislik ve Tic. A.Ş. , Ankara

${ }^{2}$ Savunma Teknolojileri Mühendislik ve Tic. A.Ș. , Ankara

${ }^{3}$ Savunma Teknolojileri Mühendislik ve Tic. A.Ş. , Ankara

(Alınış / Received: 06.06.2016, Kabul / Accepted: 12.08.2016, Online Yayınlanma / Published Online: 09.01.2017)

Anahtar Kelimeler Strateji Tasarım Kalıbı,

Fabrika Metot Tasarım Kalıbı, Açık Kapalı Tasarım Prensibi, NMEA 0183

Standard, GPS Mesajları
Özet: NMEA 0183; deniz sistemlerindeki elektronik cihazlar arasındaki iletişimde kullanılan bir standarttır. Bu uygulama bildirisinde; ilk önce NMEA 0183 standardı ile ilgili genel bilgiler verilecektir. Sonra ise; GPS alıcısından gönderilen NMEA 0183 standardındaki mesajların nesneye yönelik programlamanın temel prensiplerinden olan "genişlemeye açık fakat değişikliğe kapalı" prensibine uygun olarak strateji ve fabrika tasarım kalıpları ile yazılım tasarımının nasıl yapıldığı anlatılacaktır.

\section{Handling GPS Messages According To The Object Oriented Software Design Principles of Open for Extension, Closed for Modification Principle}

\begin{tabular}{l}
\hline Keywords \\
Strategy Design \\
Pattern, \\
Factory Method \\
Design Pattern, \\
Open Closed \\
Design Principle, \\
NMEA 0183 \\
Standard, \\
GPS Messages
\end{tabular}
\begin{abstract}
NMEA 0183 is a standard for interfacing marine electronic devices. In this application article, general information about the NMEA 0183 standard will be given first. Then, design of the software, which handles NMEA 0183 messages coming from GPS receiver, by using strategy and factory method design patterns will be discussed according to the one of the object oriented programming principle "open for extension, close for the modification".
\end{abstract}

*Sorumlu yazar: mehmetgursul@gmail.com

\section{Giriş}

NMEA 0183; deniz sistemlerinde kullanılan derinlikölçer, sonar, pusula, otomatik pilot, GPS alıcıları gibi elektronik cihazlar arasındaki iletişimde kullanılan bir standarttır. Amerika'da kurulan Ulusal Deniz Elektronik Birliği
(National Marine Electronics Association) tarafından tanımlanmıştır ve kontrol edilmektedir. Deniz uygulamalarında NMEA 0183 standardının yerini yavaş yavaş NMEA 2000 standardı almaya başlamıştır [1]. 
M.M. Gürsul, M.A. Asan, T.A. Yanar / GPS Mesajlarının Nesneye Yönelik Yazılım Tasarım Prensiplerinden Genişlemeye Açık, Değişikliğe Kapalı Prensibine Göre Ele Alınması

Tipik bir NMEA 0183

standardındaki GPS cümlesi aşağıdaki gibi bir formata sahiptir:

- <başlangıç karakteri> $<$ başlık $>,<$ veri....* ${ }^{*}<$ kontrol numarasi $><\mathrm{CR}><\mathrm{LF}>$

- Tüm NMEA 0183 standardındaki mesajlar başlangıç karakteri (starting delimeter) olarak "\$" ya da "!" karakteri ile başlar ve her bir veri alanı "," karakteri ile ayrılır.

- Kontrol numarası (checksum) değeri: \$ ve * karakterleri arasındaki karakterlerin 8 bitlik exclusive OR değeridir ('\$' ve ' $*$ ' karakterleri hesaplamaya dâhil edilmez)[2].

GPS alıcısından gönderilen ve GP ile başlayan temel mesajlardan bazıları aşağıda verilmektedir:

- GPRMC: Zaman, konum, yön ve hız bilgilerini içeren mesajdır.

- GPGLL: Zaman, konum ve durum bilgisi içeren mesajdır.

- GPGGA: Zaman, konum, kullanılan uydu sayısı, anten irtifası vb bilgileri içeren mesajdır [3].

$\mathrm{Bu}$ mesajlardan \$GPGLL mesajının formatı detaylı bir şekilde aşağıda verilmiştir.

\$GPGLL,4101.38311,N,02834.9781

2,E,065932.18,A,A*6F

- $\quad \mathrm{GP}$, bu mesajın kaynağının GPS uydu sistemi olduğunu göstermektedir. Diğer

seçenekler GLONASS uydu sistemi için GL, GNSS

sistemi kullanan aygitlar

için ise GN'dir.

- 4101.38311;

DDMM.MMMMM

formatındaki

enlem

değeridir.

- $\quad \mathrm{N}$; kuzey enlemi olduğunu belirtir

- $\quad 02834.97812$

DDDMM.MMMMM

formatındaki boylam değeridir.

- $\quad$ E; doğu boylamı olduğunu belirtir.

- *6F, kontrol toplamı (checksum) değerini gösterir.

- İlk A, durum (status) değeridir. A ise geçerli (valid), diğer durumlarda geçersiz (invalid) dir.

- İkinci A, mode indicator değeridir. Aşağıdaki değerleri almaktadır:
- A: Auto
- D: Differential
- E: Estimated
- M: Manual Input
- S: Simulator
- N: Data Invalid 
M.M. Gürsul, M.A. Asan, T.A. Yanar / GPS Mesajlarının Nesneye Yönelik Yazılım Tasarım Prensiplerinden Genişlemeye Açık, Değişikliğe Kapalı Prensibine Göre Ele Alınması

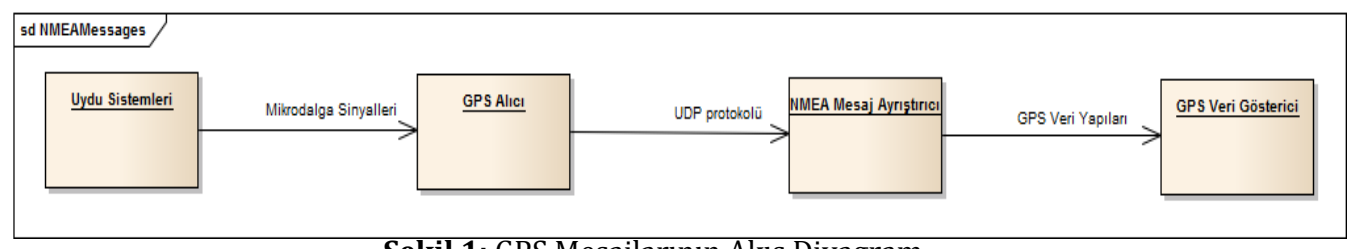

Şekil 1: GPS Mesajlarının Akış Diyagram

$\mathrm{Bu}$ uygulama bildirisinde; yukarıda adları verilen NMEA 0183 standardındaki GPS mesajlarının nesneye yönelik programlamanın temel prensiplerinden olan "open for extension, close for modification" prensibine uygun olarak nasıl bir mimari ile ele alınacağına değinilecektir.

\section{Problem}

Uydu sistemlerinden GPS alıcısına gelen mikro dalgalar, GPS alıcisı tarafından NMEA 0183 standardına uygun olarak çeşitli mesajlar halinde UDP/IP protokolü ile Ethernet kartı üzerinden gönderilmektedir (bknz. Șekil 1). Sürekli gönderilen bu mesajların Ethernet kartı üzerinden okunup, genel geçerlilik kontrolleri yapıldıktan sonra ilgili mesajın nesnesindeki verileri doldurulmak istenmektedir.

GPS alıcisı tarafindan GP ile başlayan birçok türde mesaj gönderilmektedir. GPS mesajlarını ele alan bir yazılım projesinde ihtiyaç duyulan mesajlar ele alındıktan sonra yeni ihtiyaçlara uygun olarak bașka GP ile başlayan mesajların da işlenmesi ihtiyacl doğabilmektedir. $\mathrm{Bu}$ yeni mesajları ele alırken de var olan mesajları çözümleyen kod parçalarında en az değişiklik ile yazılımın genişleyebilir olması gereklidir.

Bu ihtiyaçlara uygun şekilde Çözüm ve Tasarım bölümünde anlatılan şekilde uygulama geliștirilebilir.

\section{Cözüm ve Tasarım}

Nesneye yönelik tasarım prensipleri; kodu tasarlarken ya da yazarken uygulanan ve böylece kodun daha kolay bakımı yapılabilir, esnek ve genişleyebilir olmasını sağlayan basit temel araç ya da tekniklerdir [4]. Nesneye yönelik tasarımın beş temel prensibinin baș harflerinden olușan SOLID [5] kelimesinin içerisindeki " $O$ " harfi, "open/closed" prensibini belirtmektedir. "Open/closed" prensibi yazılım varlıklarının (sınıflar, modüller, fonksiyonlar, vb.) genişlemeye açık fakat değişikliğe kapalı olması olarak tanımlanmaktadır [4].

GPS'ten gelen NMEA 0183 standardındaki mesajların ele alınması ile ilgili tasarımda open/closed prensibine uygun olarak strateji ve fabrika metot tasarım kalıpları birlikte kullanılmıștır. Strateji ve fabrika metot tasarım kalıpları ile ilgili kısa bilgi aşağıda verilmektedir.

Strateji tasarım kalıbı, algoritmanın davranıșının çalıșma zamanında (runtime) belirlenmesini sağlayan bir yazılım tasarım kalıbıdır. Strateji tasarım kalıbı;

- Bir algoritma ailesi tanımlar,

- Her bir algoritmayı sarmalar (encapsulates),

- Algoritmanin bu algoritma ailesi içinde değiştirilebilir olmasını sağlar [6]. 
M.M. Gürsul, M.A. Asan, T.A. Yanar / GPS Mesajlarının Nesneye Yönelik Yazılım Tasarım Prensiplerinden Genişlemeye Açık, Değișikliğe Kapalı Prensibine Göre Ele Alınması

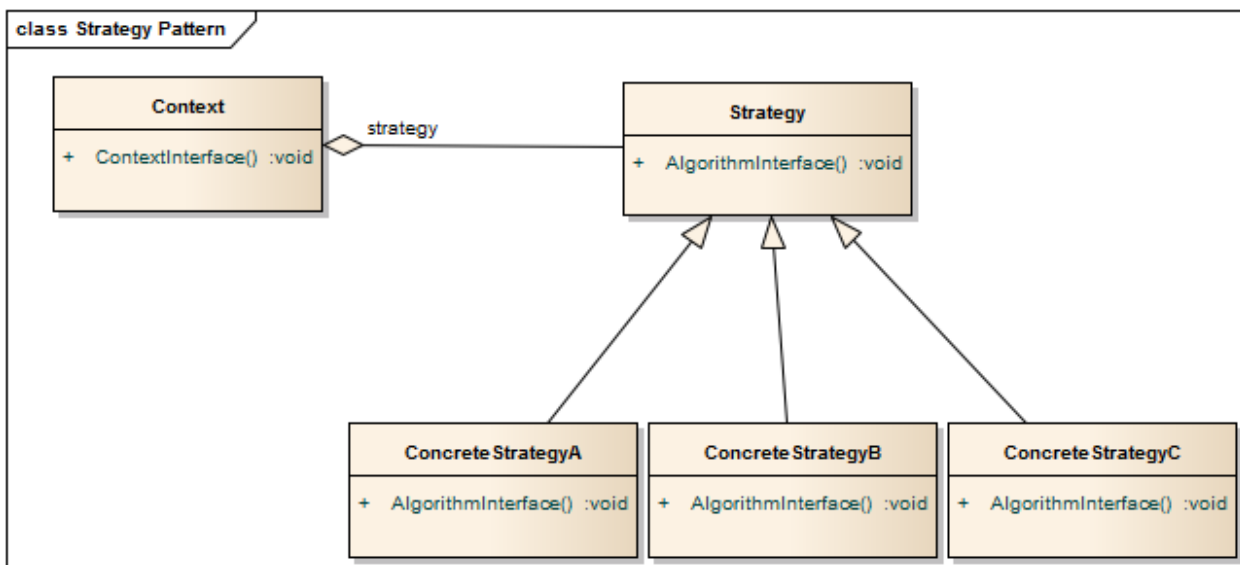

Şekil 2: Strateji Tasarım Kalıbı Sınıf Diyagramı

Strateji tasarım kalıbı sınıf ihtiyacı doğduğunda; strateji tasarım diyagramı aşağıda Şekil 2'de kalıbı sayesinde, var olan mesajlarda gösterilmektedir. herhangi bir değişiklik yapma gereği duymadan, yeni mesajı yazılıma kolayca

Fabrika metot tasarım kalıbı; nesnelerin yaratılmasını başka bir sınıfa delege eden bir yazılım tasarım kalıbıdır. Fabrika metot tasarım kalıbı ile;

- Nesne yaratılması fabrika sınıfı içinde yer alır,

- Böylece nesnenin yaratılması ve nesnenin kullanılması ayrıştırılmış olur,

- Fabrika sınıfı içindeki nesne yaratılması mantığında yapılacak değişiklik, nesne kullanımı tarafında herhangi bir değişikliğe gerek duymadan yapılabilir [6].

Fabrika metot tasarım kalıbı sınıf diyagramı aşağıda Şekil 3'te gösterilmektedir.

Strateji ve fabrika metot tasarım kalıpları Şekil 4'te gösterildiği şekilde sisteme uyarlanmıştır. Bu tasarım ile yeni bir mesajı yazılımda ele almak entegre edebilme olanağı sağlanmıș olmaktadır.

Örneğin X adında yeni bir NMEA 0183 standardındaki mesaj yazılıma eklenmek istendiğinde, strateji tasarım kalıbı sayesinde; Şekil 4'te gösterilen mesajlarda ve MessageManager sınıfında herhangi bir değişiklik yapmaya gerek kalmadan sadece aşağıda belirtilen iki eklemenin yapılması yeterli olacaktır:

- MsgXHandler şeklinde IMessageHandler arayüzünü gerçekleyen bir sınıf eklenip,

- MessageFactory sinıfinda bu yeni mesaj için <messageType, MsgXHandler> anahtar-değer (key-value) verisini eklemek yeterli olacaktır. $\mathrm{Bu}$ kısımda istenirse Dependency Injection ile kod yeniden derlemeye gerek kalmadan yapılabilir. 
M.M. Gürsul, M.A. Asan, T.A. Yanar / GPS Mesajlarının Nesneye Yönelik Yazılım Tasarım Prensiplerinden Genişlemeye Açık, Değișikliğe Kapalı Prensibine Göre Ele Alınması

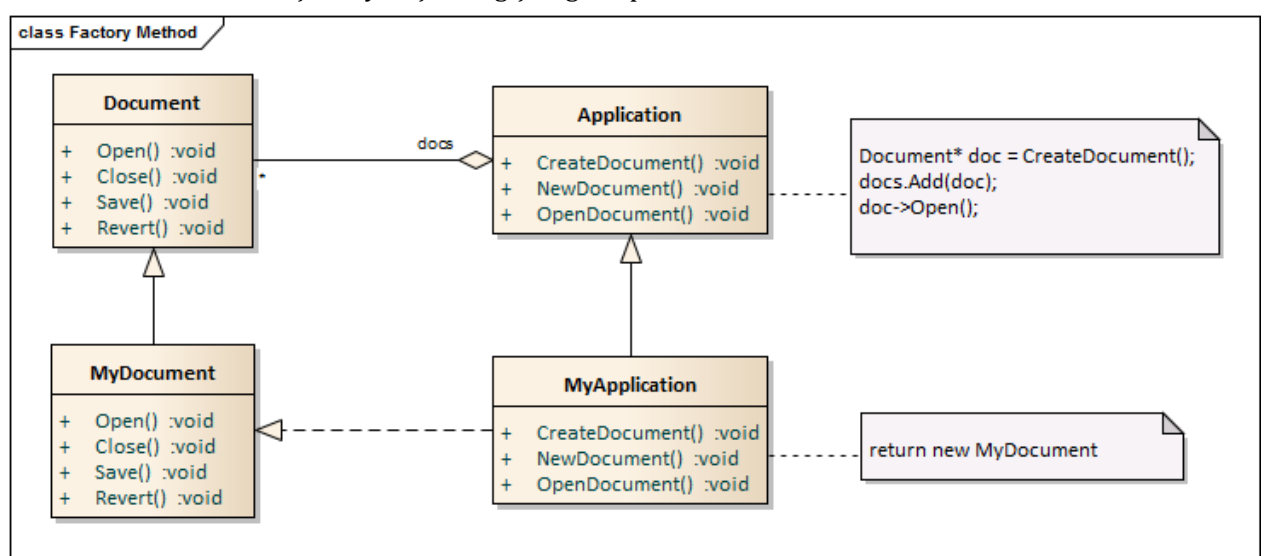

Şekil 3: Fabrika Metot Tasarım Kalıbı Sınıf Diyagramı

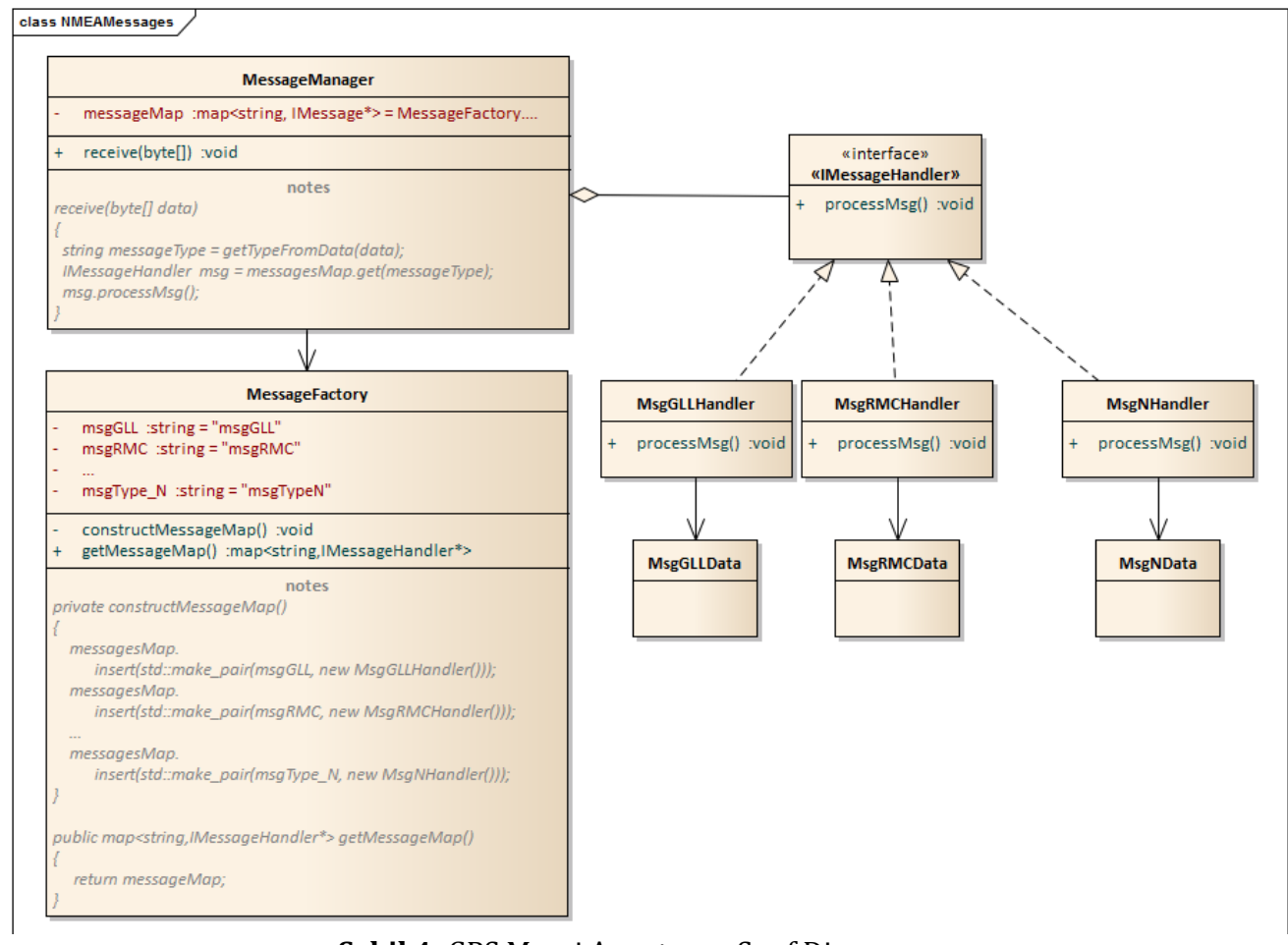

Şekil 4: GPS Mesaj Ayrıştırma Sınıf Diyagramı

Strateji tasarım kalıbının avantajlarının yanında nesne sayısını artması olarak dezavantajı da bulunmaktadır.

Diğer bir alternatif de koşullu deyimler kullanarak hangi alt sınıfin mesajı ele alacağına karar vermektir. Fakat bu şekilde yapıldığında yeni bir mesaj ele alınmak istendiğinde yeni bir koşul deyiminin eklenmesini gerektirecektir. 
M.M. Gürsul, M.A. Asan, T.A. Yanar / GPS Mesajlarının Nesneye Yönelik Yazılım Tasarım Prensiplerinden Genişlemeye Açık, Değişikliğe Kapalı Prensibine Göre Ele Alınması

\section{Tartışma ve Sonuc}

Yazılım projelerindeki temel sorunlardan birisi; yeni ihtiyaçlara uygun olarak var olan yazilımın genișleyememesi ve herhangi bir değişiklikte var olan kod parçalarında da değişiklik yapılma gerekliliğinin doğmasıdır.

Bu makale ile GPS mesajlarının ele alınacağı bir yazılım projesinin genişlemeye açık fakat var olan kodlar üzerinde de en az değişikliğe yol açacak şekildeki yazılım tasarımı ile yazılımın yeni ihtiyaçlara cevap verebilmesi sağlanmıștır. Ayrıca kod okunabilirliği ve yazılım bakımı da daha kolay duruma getirilmiştir.

\section{Kaynakça}

[1]. Standard NMEA-0183 sentences description, freenmea.net/docs, Erişim Tarihi: 16.08.2016

[2]. IEC 61162-1 Maritime navigation and radiocommunication equipment and systems - Digital interfaces - Part 1: Single talker and multiple listeners Edition 4.0, November 2010.

[3]. NMEA Data, www.gpsinformation.org/dale/nmea.ht m, Erişim Tarihi: 16.08 .2016

[4]. Head First Object-Oriented Analysis\&Design, Brett D. McLaughlin, Garry Pollice, David West, 2006, O'Reilly Media, First Edition [5]. SOLID (object-oriented design),https://en.wikipedia.org/wiki/ SOLID_(object-oriented_design), Erişim Tarihi: 20.05.2016

[6]. Design Patterns, Elements of Reusable Object-Oriented Software, Erich Gamma, Richard Helm, Ralph Johnson, John Vlissides 